\title{
KESESUAIAN PEMBANGUNAN KitAB CERDAS UNTUK KEMAHIRAN BACAAN AWAL KANAK-KANAK TASKA
}

The Effectiveness of Development KitAB Cerdas for Early Childhood Reading Skills

Rashidah Elias ${ }^{1}$, Mahizer Hamzah², Mahani Razali ${ }^{3}$

IPG Kampus Dato' Razali Ismail, Kuala Terengganu, Universiti Pendidikan Sultan Idris, Tanjong Malim, Perak rashidah@ipgm.edu.my ${ }^{1}$,mahizer@fppm.upsi.edu.my ${ }^{2}$, mahani@fppm.upsi.edu.my ${ }^{3}$

\section{ABSTRAK}

Kajian ini dijalankan bertujuan meninjau kesesuaian pembangunan kit bacaan awal yang dinamakan KitAB Cerdas untuk memberikan kemahiran bacaan awal kepada kanak-kanak TASKA. Kajian dijalankan menggunakan reka bentuk kajian tinjauan secara kuantitatif. Seramai 59 orang responden terlibat dari kalangan pendidik dan ibu bapa kanak-kanak TASKA Yayasan Pembangunan Keluarga Terengganu. Instrumen kajian merupakan soal selidik analisis keperluan. Dapatan kajian menunjukkan bahawa KitAB Cerdas perlu dibangunkan untuk membantu pembelajaran bacaan awal kanak-kanak. Dapatan kajian juga menunjukkan bahawa media pembelajaran yang dicadangkan adalah sesuai untuk dimasukkan ke dalam KitAB Cerdas. Secara keseluruhan, KitAB Cerdas sesuai dibangunkan untuk membantu kanak-kanak TASKA memperoleh kemahiran bacaan awal dalam suasana yang menggembirakan. Kajian ini telah memberi implikasi bahawa pembangunan KitAB Cerdas memberikan impak kepada pemerolehan bacaan awal kanak-kanak TASKA. 
Kata Kunci: Kit $\mathrm{AB}$ Cerdas, bacaan awal, analisis keperluan, kajian tinjauan, pembangunan kit bacaan awal

\section{ABSTRACT}

This study aims to survey the appropriateness of developing a kit for early reading called KitAB Cerdas to help the nursery children in acquiring early reading skill. This is a quantitative study using survey design. A total of 59 respondents participated consisting educators and parents of Yayasan Pembangunan Keluarga Terengganu nurseries. The instrument used was needs analysis questionnaire. The findings indicated that KitAB Cerdas need to be developed to help the nursery children in acquiring the early reading skill. Findings also showed that the proposed instructional media was suitable to be included in the KitAB Cerdas. Generally, the development of KitAB Cerdas is suitable to help the nursey children in acquiring the early reading skill in a joyful environment. This study implicates that the development of KitAB Cerdas can give positive impact on the acquisition of early reading skill for nursery children.

Keywords: KitAB Cerdas, early reading, needs analysis, survey design, development of early reading kit

\section{PENGENALAN}

Kemahiran membaca adalah kemahiran asas yang mempengaruhi setiap aspek dalam pembelajaran kanak-kanak. Kajian telah membuktikan bahawa penguasaan kemahiran membaca menjadi jambatan untuk kanak-kanak menggarap ilmu, pembelajaran dan pengalaman baru (Bingham \& Patton-Terry, 2013; Lane, O'Shaughnessy, Lambrose, Gresham \& Beebe-Frankenberger, 2001; Mohd.Yusof, 2002; Morocco, 2001). Dapatan kajian oleh Mohd. Yusof (2002) menunjukkan bahawa kanak-kanak yang 
Jurnal Pendidikan Awal Kanak-Kanak Kebangsaan 2017 Special Issue (32-47)

(ISSN 2289-3032 / eISSN 2550-178X)

https://ejournal.upsi.edu.my/journal/JPAK

tidak dapat menguasai kemahiran membaca akan menghadapi masalah untuk memahami mata pelajaran lain. Masalah ini berterusan apabila kanak-kanak meneruskan pendidikan mereka ke persekolahan formal seperti yang dilaporkan oleh Hornery, Seaton, Tracey, Craven, \& Yeung (2014), malahan boleh berlanjutan sehingga ke sekolah menengah. Keperluan menguasai kemahiran membaca tidak dapat dinafikan sesuai dengan petikan daripada Kitab Al-Quran dalam Surah Al-Alaq yang bermaksud:

"Bacalah (wahai Muhamad) dengan nama Tuhanmu yang menciptakan (sekalian makhluk). Ia menciptakan manusia daripada segumpal darah.

Bacalah, dan Tuhanmu Yang Maha Pemurah. Yang mengajarkan manusia melalui pena dan tulisan. Ia mengajarkan manusia apa yang tidak diketahuinya."

(Surah al-Alaq: 1-5)

Galakan terhadap perolehan bacaan awal perlu diberikan sejak usia awal kanak-kanak.Mungkin terdapat sesetengah pihak berpendapat bahawa kanak-kanak berumur antara tiga hingga empat tahun belum bersedia untuk membaca, namun demikian sebenarnya kanak-kanak sentiasa bersedia untuk membaca (Cullingford, 2001; Lonigan, Shanahan \& Cunningham, 2008). Pada zaman ini pula tidak kurang kanak-kanak berumur tiga hingga empat tahun telah mula mampu membaca (Mahzan, 2012) iaitu pada peringkat bacaan awal, walaupun belum mencapai tahap bacaan lancar.

Peringkat umur kanak-kanak antara tiga hingga empat tahun seperti yang disebutkan di atas merujuk kepada pembelajaran di taman asuhan kanak-kanak (TASKA) di Malaysia. Pendidik di TASKA perlu memahami konsep bacaan awal supaya pendidik awal kanak-kanak boleh membimbing kanak-kanak berdasarkan tahap kemahiran mereka. Bacaan awal merupakan peringkat di mana kanak-kanak mula diperkenalkan dengan cetakan atau simbol sama ada berbentuk huruf-huruf atau gambar-gambar dalam bahasa 
yang tertentu (Yahya, 2007). Kemahiran bacaan awal adalah peringkat paling penting yang perlu dikuasai kanak-kanak dalam keseluruhan proses pembelajaran membaca (Naimah, Nor Hashimah \& Hashim, 2011). Peringkat bacaan awal muncul selepas kanak-kanak menguasai peringkat literasi awal dan sebelum mampu membaca dengan lancar. Kesemua proses perolehan kemahiran literasi awal, bacaan awal dan bacaan lancar bersifat mengikut urutan, bertindan kemahiran dan menambah tanpa menghilangkan kemahiran-kemahiran kecil sebelumnya, seperti yang digambarkan oleh Rashidah (2012) melalui Rajah 1.

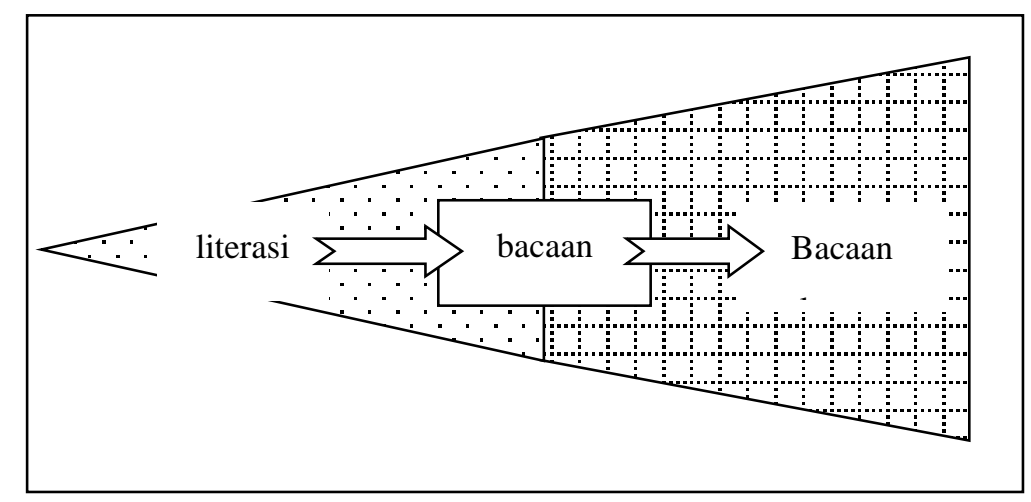

Rajah 1: Zon kemahiran bacaan awal

Berdasarkan Rajah 1, kemahiran bacaan awal diperoleh selepas kanak-kanak menguasai peringkat literasi awal. Namun demikian dalam proses memperoleh kemahiran bacaan awal Tompkins (2003) menyebut berlaku juga fasa tunas bacaan. Ciri-ciri tunas bacaan dan bacaan awal yang disebutkan oleh Tompkins disenaraikan seperti dalam Jadual 1 di bawah.

Jadual 1: Ciri-ciri Kanak-kanak Pada Peringkat Tunas Bacaan Dan Bacaan Awal

\section{Tunas Bacaan}

- Menyedari cetakan di persekitaran

\section{Bacaan Awal}

- Dapat mengecam nama huruf dan bunyinya 
Jurnal Pendidikan Awal Kanak-Kanak Kebangsaan 2017 Special Issue (32-47)

(ISSN 2289-3032 / eISSN 2550-178X)

https://ejournal.upsi.edu.my/journal/JPAK

- Menunjukkan minat kepada buku

- Memadankan perkataan lisan dengan cetakan

- Berpura-pura membaca

- Mengecam 20-100 perkataan yang biasa dengannya

- Menggunakan gambar dalam buku - Menggunakan bunyi awalan, dan jangkaan sendiri menceritakan pertengahan dan akhiran perkataan semula isi buku untuk mentafsir perkataan

- Membaca buku yang biasa dengan

- Menggunakan pengetahuan sistem mereka secara berulang kali dengan isyarat (cue) untuk membaca jangkaan cerita sendiri

- Mengenal sebilangan kecil nama huruf

- Membetulkan sendiri semasa membaca

- Mengecam 5-10 perkataan berulang

- Membuat jangkaan yang munasabah (high frequency words) dalam cerita yang dibacakan kepadanya

- Cuba menghubungkan diri dengan teks

- Menghubungkan teks dengan diri dan teks dengan dunia sekitaran

Ciri-ciri yang disenaraikan dalam Jadual 1 juga menjelaskan proses pertindanan kemahiran yang telah disebutkan sebelum ini. Pendidik awal kanak-kanak di TASKA boleh menjadikan ciri-ciri tersebut sebagai panduan dalam membimbing kanak-kanak memperoleh dan menguasai kemahiran bacaan awal.

Pembelajaran bacaan awal untuk kanak-kanak perlu menggunakan kaedah yang menyeronokkan dan mampu merangsang pelbagai deria mereka. Kanak-kanak belajar melalui bermain (Nor Hashimah \& Yahya, 2003) di mana bermain dan bergerak merupakan lumrah mereka. Bermain mampu menggembirakan kanak-kanak, menyebabkan hilang tekanan dan dapat melepaskan tenaga berlebihan dalam tubuh badan mereka (Isenberg \& Jalongo, 2001). Selain daripada itu, lumrah kanak-kanak juga gemarkan 
muzik dan nyanyian. Rangsangan yang pelbagai akan menarik perhatian kanak-kanak dan meningkatkan pengamatan mereka seperti objek yang bersaiz besar, perubahan situasi, kekuatan bunyi dan warna, muzik dan pergerakan (Hasnah \& Habibah, 2010).

\section{Masalah Kajian}

Seperti yang telah dibincangkan di atas, kanak-kanak memerlukan teknik pembelajaran bacaan awal yang memenuhi minat dan lumrah mereka. Namun demikian terdapat isu di mana pendidik awal kanak-kanak mengajar bacaan awal dalam bentuk yang formal seperti sekolah rendah (Chiam, 2003). Aktiviti yang paling kerap digunakan oleh guru untuk pengajaran membaca adalah latih tubi (Che Puteh, 2009; Salimah, 2004). Kit pembelajaran bacaan awal pula banyak dibina secara berasingan, bukan dihimpunkan dalam satu set kit pembelajaran yang lengkap (Hourcade et al., 2010; Jenkins, 2005; Kamisah, 2011; Mohamizzam, 2006; Nita@Siti Raudhah, 2003; Suries, 2007).

\section{Objektif Kajian}

Objektif kajian ini dijalankan adalah untuk:

(i) Meninjau kesesuaian pembangunan KitAB Cerdas sebagai bahan bantu pembelajaran bacaan awal untuk kanak-kanak TASKA.

(ii) Meninjau kesesuaian media yang dicadangkan untuk KitAB Cerdas.

\section{Soalan Kajian}

Sebagai memenuhi objektif kajian, dua soalan yang perlu dijawab dalam kajian ini adalah:

(i) Adakah KitAB Cerdas sesuai untuk dibangunkan?

(ii) Adakah media pembelajaran yang dicadangkan sesuai untuk dimasukkan ke dalam KitAB Cerdas? 
Jurnal Pendidikan Awal Kanak-Kanak Kebangsaan 2017 Special Issue (32-47)

(ISSN 2289-3032 / eISSN 2550-178X)

https://ejournal.upsi.edu.my/journal/JPAK

\section{Tinjauan Literatur}

Pembelajaran bacaan awal untuk kanak-kanak menuntut satu bentuk bahan bantu pembelajaran yang memenuhi minat dan lumrah kanak-kanak. Pembelajaran bacaan awal tidak sesuai dilakukan secara latih tubi semata-mata (Che Puteh, 2009; Salimah, 2004). Bahan bantu tidak kira berbentuk elektronik atau bukan elektronik merupakan bahan sokongan yang penting untuk meningkatkan kefahaman kanak-kanak, mengekalkan minat belajar dan dapat menjelaskan mesej yang ingin disampaikan (Agarwal \& Dhanasekaran, 2012; Aliza \& Zamri, 2015). Kanak-kanak berminat dengan aktiviti literasi dan aktiviti bacaan awal apabila pelbagai media digunakan sebagai bahan bantu dalam pembelajaran mereka (Hawkins, Green \& Clark, 2010).

Buku cerita bergambar mampu menarik minat kanak-kanak untuk membaca, mengenal huruf dan perkataan dengan lebih mudah (Owens, 2005) serta memberikan ruang kepada kanak-kanak untuk membuat perkaitan dengan kehidupan dan budaya mereka (Mantei \& Kervin, 2014). Walaupun tanpa perkataan, gambar dalam buku masih boleh menggalakkan penyertaan aktif dan meningkatkan kemahiran berfikir Arizpe (2013). Sementara itu, kad imbasan merupakan media tradisional, namun masih relevan sebagai bahan bantu yang berkesan dalam pembelajaran bacaan awal (Budden, 2014; Norasikin, 2007; Gan, 2009).

Kepelbagaian media sebagai bahan bantu pembelajaran bacaan awal membawa manfaat yang besar kepada kanak-kanak. Pembelajaran bacaan awal yang disepadukan dengan teknik main menjadikan kanak-kanak bersemangat dan dapat menggalakkan penglibatan aktif, memandangkan main merupakan fokus dalam kehidupan kanak-kanak. Dapatan kajian oleh Che Puteh (2009) dan Mohamad Daud (2002) telah menunjukkan bahawa 
kanak-kanak mempunyai minat yang tinggi terhadap pembelajaran apabila teknik main digunakan dan berani mencuba walaupun pada asalnya agak malu. Selain daripada itu, muzik, kad imbasan, gerakan dan TMK telah dapat membantu kanak-kanak orang asli menguasai kemahiran membaca (Norasikin, 2007). Lagu pula didapati telah membantu murid mengecam dan mengenal bentuk huruf kecil di samping mampu mengurangkan tekanan dan menyebabkan murid yakin pada diri (Zurinah, 2010).

Pembelajaran pada abad ke-21 ini menuntut kanak-kanak mempunyai kemahiran dalam teknologi komputer walaupun pada usia awal mereka. Seperti yang dilaporkan Tucker (2014) keperluan terhadap teknologi komputer adalah menyeluruh untuk semua keluarga tanpa mengira latar belakang ekonomi mereka. Ini disokong oleh dapatan kajian Kamisah (2011) yang menunjukkan bahawa pembelajaran bacaan awal menggunakan bahan multimedia dapat merangsang minat kanak-kanak dan meningkatkan prestasi mereka (Kamisah, 2011). Kajian oleh John (2009) pula mendapati murid dapat mengeja perkataan dengan susunan suku kata KVKV menggunakan gambar dalam perisian komputer. Selain daripada itu, aplikasi perisian komputer didapati telah membantu meningkatkan kemahiran literasi awal (Hourcade et al., 2010) dan boleh meningkatkan kesedaran fonologi dalam kalangan kanak-kanak bawah empat tahun (Puolakanaho, Poikkeus, Ahonen, Tolvanen, \& Lyytinen, 2003; US Department of Education, 2013).

\section{Metodologi}

Reka bentuk kajian ini merupakan reka bentuk tinjauan yang menggunakan kaedah kuantitatif. Kajian ini merupakan kajian analisis keperluan yang dijalankan sebelum pembangunan KitAB Cerdas dilaksanakan. Seramai 59 orang responden terlibat dari kalangan pendidik dan ibu bapa kanak-kanak TASKA Yayasan Pembangunan Keluarga Terengganu (YPKT). Instrumen kajian terdiri daripada soal selidik analisis keperluan. Dapatan soal selidik 
Jurnal Pendidikan Awal Kanak-Kanak Kebangsaan 2017 Special Issue (32-47)

(ISSN 2289-3032 / eISSN 2550-178X)

https://ejournal.upsi.edu.my/journal/JPAK

dianalisis secara deskriptif dan dipersembahkan dalam bentuk jadual frekuensi dan peratusan.

\section{Dapatan Kajian dan Perbincangan}

Topik-topik kecil dalam bahagian ini yang akan dibincangkan adalah berdasarkan kepada objektif dan soalan kajian yang perlu dijawab.

\section{Keperluan Pembangunan KitAB Cerdas}

Dapatan kajian menunjukkan bahawa KitAB Cerdas perlu dibangunkan untuk membantu pembelajaran bacaan awal kanak-kanak. Keperluan ini ditunjukkan seperti dalam Jadual 2 di bawah.

Jadual 2: Keperluan Pembangunan Kit Bacaan Awal (KitAB Cerdas)

\begin{tabular}{|c|c|c|c|c|c|c|c|c|}
\hline & & \multirow[t]{2}{*}{$\mathbf{N}$} & \multicolumn{2}{|c|}{$\begin{array}{l}\text { Kit bacaan } \\
\text { awal perlu } \\
\text { dibangunkan }\end{array}$} & \multicolumn{2}{|c|}{$\begin{array}{l}\text { Kit yang } \\
\text { dicadangkan } \\
\text { sesuai untuk } \\
\text { menyokong } \\
\text { kurikulum } \\
\end{array}$} & \multicolumn{2}{|c|}{$\begin{array}{l}\text { Kit yang } \\
\text { dicadangkan } \\
\text { dapat } \\
\text { memudahkan } \\
\text { pembelajaran }\end{array}$} \\
\hline & & & Ya & Tidak & Ya & Tidak & Ya & Tidak \\
\hline Pendidik & & 20 & 20 & 0 & 20 & 0 & 20 & 0 \\
\hline Ibu bapa/penjaga & & 39 & 37 & 2 & 37 & 2 & 37 & 2 \\
\hline \multirow[t]{2}{*}{ Jumlah } & $F$ & 59 & 57 & 2 & 57 & 2 & 57 & 21 \\
\hline & $\%$ & 100.0 & 96.6 & 3.4 & 96.6 & 3.4 & 96.6 & 3.4 \\
\hline
\end{tabular}

Berdasarkan Jadual 1, seramai 57 daripada 59 orang (96.6\%) responden bersetuju bahawa satu kit bacaan awal perlu dibangunkan untuk membantu pembelajaran bacaan awal kanak-kanak. Bilangan yang sama juga iaitu 57 
orang (96.6\%) menyatakan bahawa kit bacaan awal boleh menyokong kurikulum pendidikan awal kanak-kanak. 57 orang (96.6\%) responden yang sama juga menyatakan bahawa kit bacaan awal akan memudahkan bimbingan terhadap pembelajaran bacaan awal kanak-kanak. Oleh itu boleh dirumuskan di sini bahawa berdasarkan persepsi pendidik dan ibu bapa/penjaga kanak-kanak, pembelajaran bacaan awal sesuai dimulakan untuk kanak-kanak 3+ dan perlu satu bentuk kit bacaan awal dibangunkan untuk tujuan tersebut. Kit bacaan awal perlu sesuai untuk menyokong kurikulum pendidikan awal kanak-kanak dan dapat membantu dalam pembelajaran bacaan awal.

\section{Kesesuaian Media yang Dicadangkan}

Pengkaji telah mencadangkan beberapa media pembelajaran untuk dimasukkan ke dalam KitAB Cerdas. Sebahagian item soal selidik menyentuh tentang persetujuan pendidik dan ibu bapa terhadap media yang dicadangkan untuk pembelajaran bacaan awal. Dapatan kajian untuk bahagian ini ditunjukkan dalam Jadual 2 di bawah.

Jadual 2: Persetujuan Pendidik dan Ibu Bapa/Penjaga Terhadap Jenis Media yang Dicadangkan

\begin{tabular}{lllll}
\hline \multirow{2}{*}{ Jenis Media } & $\begin{array}{l}\text { Pendidik } \\
\text { TASKA }\end{array}$ & Ibu Bapa & Jumlah & \\
& $\boldsymbol{f}$ & $\boldsymbol{\%}$ & $\boldsymbol{f}$ & $\boldsymbol{\%}$ \\
\hline Kad imbasan (suku kata) & 20 & 35 & 55 & 96.5 \\
Alat permainan & 19 & 32 & 51 & 89.5 \\
Lagu & 20 & 33 & 53 & 93.0 \\
Buku bacaan & 18 & 33 & 51 & 89.5 \\
Buku besar elektronik & 19 & 27 & 46 & 80.7 \\
Perisian komputer & 19 & 24 & 43 & 75.4 \\
Buku panduan & 20 & 37 & 57 & 100.0 \\
\hline
\end{tabular}


Jurnal Pendidikan Awal Kanak-Kanak Kebangsaan 2017 Special Issue (32-47)

(ISSN 2289-3032 / eISSN 2550-178X)

https://ejournal.upsi.edu.my/journal/JPAK

$$
f=\text { frekuensi } \quad \%=\text { peratus } \quad \mathrm{N}=57
$$

Media yang telah dicadangkan oleh pengkaji untuk dimasukkan ke dalam KitAB Cerdas termasuklah kad imbasan, alat permainan, lagu, buku bacaan, buku besar elektronik, dan perisian komputer. Selain daripada itu, buku panduan juga dicadangkan untuk memudahkan pendidik menggunakan KitAB Cerdas untuk membimbing pembelajaran bacaan awal kanak-kanak. Berdasarkan Jadual 2, dapat dilihat bahawa sebahagian besar responden bersetuju dengan kesemua media, termasuk buku panduan yang dicadangkan. Media yang paling kurang dipersetujui adalah perisian komputer di mana seramai 43 orang (75.4\%) responden bersetuju media ini dimasukkan dalam KitAB Cerdas, Namun demikian, oleh sebab persetujuan tersebut melebihi $50 \%$, maka pengkaji menilai dan mengambil keputusan bahawa media ini juga dimasukkan dalam KitAB Cerdas.

\section{Perbincangan dan Rumusan}

Sesuatu bahan bantu pembelajaran tidak boleh dibangunkan dengan sewenang-wenangnya. Pembangunan bahan bantu pembelajaran perlu dilaksanakan dalam satu proses sistematik menggunakan model pembangunan bahan yang khusus. Hal ini bagi menjamin bahan pembelajaran yang dihasilkan berkualiti dan sesuai untuk digunakan oleh golongan sasar (Smaldino, Lowther \& Russell, 2012). Dalam kajian ini analisis keperluan dijalankan untuk memastikan keperluan terhadap pembangunan KitAB Cerdas. Selain daripada itu media yang dicadangkan untuk dimasukkan ke dalam KitAB Cerdas juga perlu dipastikan kesesuaiannya.

Walaupun kumpulan sasaran dalam kajian ini adalah berfokus kepada kanak-kanak, pendidik juga merupakan kumpulan sasaran yang menggunakan kit bacaan awal dalam kajian ini kerana peranan mereka 
sangat penting dalam membimbing kanak-kanak melalui scaffolding (Vygotsky, 1986). Pandangan ibu bapa ditanya kerana mereka juga merupakan orang yang penting untuk menyokong pembelajaran kanak-kanak di rumah. Berdasarkan dapatan kajian, KitAB Cerdas sesuai dibangunkan untuk pembelajaran bacaan awal kanak-kanak TASKA. Kit yang dicadangkan juga dapat menyokong kurikulum pendidikan awal kanak-kanak sedia ada iaitu Kurikulum PERMATA Negara (Jabatan Perdana Menteri, 2013). Kesesuaian pembangunan KitAB Cerdas juga selari dengan apa yang dinyatakan oleh Mahzan (2012) di mana dalam era ini kanak-kanak berumur tiga hingga empat tahun sudah boleh diajar bacaan awal kerana kesediaan telah ada dalam diri kanak-kanak sejak mula lagi (Cullingford, 2001; Lonigan, Shanahan \& Cunningham, 2008).

Berdasarkan dapatan kajian juga, kesemua media yang telah dicadangkan dipersetujui oleh responden terlibat. Kepelbagaian media yang dimuatkan dalam KitAB Cerdas menjadi satu fokus utama supaya kanak-kanak mempunyai peluang untuk menggunakan media yang disenangi oleh mereka semasa mempelajari bacaan awal. Kepelbagaian media yang dimuatkan dalam KitAB Cerdas juga bagi mengatasi masalah pembangunan media yang terpisah-pisah sebelum ini (Hourcade et al., 2010; Jenkins, 2005; Kamisah, 2011; Mohamizzam, 2006; Nita@Siti Raudhah, 2003; Suries, 2007). Melalui pembangunan KitAB Cerdas, banyak media dapat dihimpunkan, sesuai dengan cadangan kajian oleh Kamisah (2011). Kepelbagaian media yang dihimpunkan dalam KitAB Cerdas dijangka dapat membantu pendidik, terutama pendidik baharu untuk mengajar bacaan awal. Selain daripada itu, media yang berasakan kepada teknologi memenuhi keperluan pembelajaran abad ke-21 yang sedang berkembang dengan pesat.

\section{PENUTUP}

Secara keseluruhan, KitAB Cerdas sesuai dibangunkan untuk membantu 
Jurnal Pendidikan Awal Kanak-Kanak Kebangsaan 2017 Special Issue (32-47)

(ISSN 2289-3032 / eISSN 2550-178X)

https://ejournal.upsi.edu.my/journal/JPAK

kanak-kanak TASKA memperoleh kemahiran bacaan awal dalam suasana yang menggembirakan. Kepelbagaian media yang dimuatkan dalam KitAB

Cerdas dilihat boleh memberi ruang dan peluang yang lebih luas kepada kanak-kanak untuk membuat pilihan media dalam proses pembelajaran bacaan awal. Kajian ini memberi implikasi bahawa pembangunan KitAB Cerdas memberikan impak kepada pemerolehan bacaan awal kanak-kanak TASKA dalam arus perkembangan teknologi pendidikan dalam abad ke-21 ini.

\section{RUJUKAN}

Agarwal, V. \& Dhanasekaran, S. (2012). Harmful effects of media on children and adolescents. Journal of Indian Association for Child and Adolescent Mental Health, 8(2), 38-45.

Aliza Ali \& Zamri Mahamod. (2015). Analisis keperluan terhadap pengguna sasaran modul pendekatan berasaskan bermain bagi pengajaran dan pembelajaran kemahiran bahasa kanak-kanak prasekolah. Jurnal Kurikulum dan Pengajaran Asia Pasifik, 3(1), 1-8.

Al-Quran. Surah al-Alaq. Ayat 1-5.

Arizpe. (2013). Meaning-making from wordless (or nearly wordless) picture books:

What educational research experts have to say. Cambridge Journal of Education, 43(2), 163-176. ISSN 0305-764X. Dimuat turun daripada http://eprints.gla.ac.uk/76005/1/76005.pdf

Bingham, G. E., \& Patton-Terry, N. (2013). Early language and literacy achievement of Early Reading First students in kindergarten and 1st grade in the United States. Journal of Research in Childhood Education, 27(4), 440-453. doi:10.1080/02568543.2013.822952

Budden, J. (2014). Using flash cards with young learners. Diakses daripada laman web British Council https://www.teachingenglish.org.uk/article/using-flash-cards-young-learners

Che Puteh Hanapiah. (2009). Sebuca: Menguasai huruf besar dan kecil. Tuntas 5, 
1-10. Alor Setar: Jabatan Pelajaran Negeri Kedah.

Chiam H. K. (2003). Kertas Kerja Seminar dan Pameran Perdana Prasekolah 2003.

Petaling Jaya, Selangor.

Cullingford, C. (2001). How children learn to read. London: Kogan Page.

Gan Geok Keng. (2009). Keberkesanan penggunaan kad imbasan dalam pengajaran dan pembelajaran membaca di prasekolah (Laporan penyelidikan yang tidak diterbitkan). Universiti Malaya, Petaling Jaya.

Hasnah Awang \& Habibah Mohd. Samin. (2010). Literasi Bahasa Melayu. Subang Jaya: Kumpulan Budiman Sdn. Bhd.

Hawkins, L., Green, R., \& Clark, C. (2010). Evaluating the effectiveness of Early Reading Connects Approach: A six month-study of 16 early years setting in Dudley. Dimuat turun daripada laman web National Literacy Trust http://www.literacytrust.org.uk/resources/practical_resources_info/1963_reportevaluating_the_effectiveness_of_the_early_reading_connects_approach

Hornery, S., Seaton, M., Tracey, D., Craven, R. G., \& Yeung, A. S. (2014). Enhancing reading skills and reading self-concept of children with reading difficulties: Adopting a dual approach intervention. Australian Journal of Educational and Developmental Psychology, 14, 131-143.

Hourcade, J.J., Parette Jr., H. P., Boeckmann, N., \& Blum, C. (2010). Handy Manny and the emergent literacy technology toolkit. Early Childhood Education Journal, 37, 483-491. doi:10.1007/s10643-010-0377-1.

Isenberg, J. A., \& Jalongo, M. R. (2001). Creative expression and play in early childhood (3rd ed.). New Jersey: Prentice Hall.

Jabatan Perdana Menteri. (2013). Kurikulum PERMATA Negara. Asuhan dan didikan awal kanak-kanak 0 - 4 tahun. Cyberjaya: Jabatan Perdana Menteri.

Jenkins, K. L. (2005). The effects of parental involvement strategies on elementary at-risk students'oral reading accuracy levels (Doctoral dissertation). Dimuat turun daripada http://search.proquest.com.ezpustaka.upsi.edu.my/pqdtft/docview/304994524/1 377803B7795A9E84E/2?accountid=13155 (UMI Number: 3208690)

John, C. (2009). Kaedah sebut, eja dan bunyikan. In Seminar penyelidikan IPGM 
Jurnal Pendidikan Awal Kanak-Kanak Kebangsaan 2017 Special Issue (32-47)

(ISSN 2289-3032 / eISSN 2550-178X)

https://ejournal.upsi.edu.my/journal/JPAK

KBL (pp. 113-120). Batu Lintang: IPG Kampus Batu Lintang.

Kamisah Buang. (2011). Pembangunan dan pengujian modul intervensi membaca Bahasa Melayu prasekolah berbantukan multimedia (Tesis doktor falsafah yang tidak diterbitkan). Universiti Kebangsaan Malaysia, Bangi.

Lane, K. L., O’Shaughnessy, T. E., Lambrose, K. M., Gresham, F. M., \& Beebe-Frankenberger, M.E. (2001). The efficacy of phonological awareness training with first grade students who have behavior problems and reading difficulties. Journal of Emotional and Behavioral Disorders, 9, 219-231.

Lonigan, C. J., Shanahan, T., \& Cunningham, A. (2008). Impact of shared reading interventions on young children's early literacy skills. In Developing early literacy: Report of the National Early Literacy Panel (pp. 153-171). Dimuat turun daripada laman web http://lincs.ed.gov/publications/pdf/NELPSummary.pdf

Mohamad Daud Mohamad. (2002). Aplikasi teknik permainan bahasa dalam pengajaran dan pembelajaran Bahasa Melayu. Prosiding Seminar Kebangsaan Pengajaran dan Pembelajaran Bahasa Melayu dan Bahasa Inggeris, 31 - 33. Kuala Lumpur: Kementerian Pendidikan Malaysia.

Mohd. Yusof Abd. Rahman. (2002). Perkaitan antara tingkah laku dan strategi keibubapaan dengan pencapaian matematik anak sekolah rendah di luar bandar (Latihan ilmiah sarjana yang tidak diterbitkan). Universiti Kebangsaan Malaysia, Bangi.

Morocco, C. C. (2001). Teaching for understanding with students with disabilities: New directions for research on access to the general education curriculum. Learning Disability Quarterly, 2(24), 5-13.

Mahzan Arshad. (2012). Pendidikan literasi awal kanak-kanak: Teori dan amali. Tanjong Malim: Penerbit Universiti Pendidikan Sultan Idris.

Mantei, J., \& Kervin, L. (2014). Interpreting the images in a picture book: Students make connections to themselves, their lives and experiences. English Teaching: Practice and Critique, 13(2). 76-92. Dimuat turun daripada http://eric.ed.gov/?q=picture+books+for+children\&pr=on\&ft=on\&ff1=dtySince 2010\&id=EJ1042515 
Mohamizzam Mohammad. (2006). Development of a multimedia courseware prototype for the Komponen Kesusasteraan Melayu in Bahasa Melayu subject (Master thesis). Dimuat turun daripada http://www.lib.upm.edu.my/

Naimah Yusoff, Nor Hashimah Hashim \& Hashim Othman. (2011). Kemahiran Bacaan Awal Bahasa Melayu Prasekolah. Pulau Pinang: Penerbit Universiti Sains Malaysia.

Nita @ Siti Raudhah Amri. (2003). Kesan pengajaran pembelajaran (P\&P) inkuiri berbantu teknologi maklumat dan komunikasi (ICT) terhadap pencapaian dalam mata pelajaran Sains (Biologi) bagi pelajar tingkatan 2 di SMKA (Tesis sarjana yang tidak diterbitkan). Universiti Putra Malaysia, Serdang.

Norasikin Ismail. (2007). Bacalah sayang: KIA2M SK Pangkalan Tereh, Kluang. Prosiding Seminar Penyelidikan Pendidikan Institut Pendidikan Guru Zon Selatan 2007, 67 - 72. Durian Daun: Institut Perguruan Perempuan Melayu Melaka.

Nor Hashimah Hashim, \& Yahya Che Lah. (2003). Panduan pendidikan prasekolah. Bentong: PTS Publications \& Distributors Sdn. Bhd.

Owens, R.E. Jr. (2005). Language development:An introduction. ( $7^{\text {th }}$. Ed.). New York: Pearson.

Puolakanaho, A., Poikkeus, A., Ahonen, T., Tolvanen, A., \& Lyytinen, H. (2003). Assessment of three-and-a-half-year-old children's emerging phonological awareness in a computer animation context. Journal of Learning Disabilities, 36(5), 416-423.

Rashidah Elias. (2012). Meniti Usaha Memulakan Pembelajaran Bacaan Awal Untuk Kanak-kanak TASKA Melalui Penggunaan Kit Rangsangan Kecerdasan Pelbagai. National Colloquium of Postgraduate Research in Education. Kertas kerja yang dibentangkan di Universiti Sains Malaysia, 6-7 Jun 2012 (pp. 16-27). Gelugor, Pulau Pinang: Universiti Sains Malaysia.

Salimah Mahdin. (2004). Pelaksanaan dan masalah pengajaran bacaan dalam kelas pemulihan sekolah-sekolah rendah di Bahau Negeri Sembilan (Tesis sarjana yang tidak diterbitkan). Universiti Malaya, Kuala Lumpur.

Smaldino, S.E., Lowther, D.L., \& Russell, J.D. (2012). Instructional technology and 
Jurnal Pendidikan Awal Kanak-Kanak Kebangsaan 2017 Special Issue (32-47)

(ISSN 2289-3032 / eISSN 2550-178X)

https://ejournal.upsi.edu.my/journal/JPAK

media for learning (10th ed.). Boston: Pearson Education Inc.

Suries, S. (2007). A military child initiative. Exceptional Parent, 37(7), 82-83.

Dimuat turun daripada

http://ehis.ebscohost.com.ezpustaka.upsi.edu.my/ehost/search/basic?sid=58909

694-b31e-43bb-8578-d14cad7c8cda\%40sessionmgr112\&vid=2\&hid=109

Tompkins, G. E. (2003). Literacy for the $21^{\text {st }}$. century. Teaching reading and writing in pre-kindergarten through grade 4. New Jersey: Pearson Education Inc.

Tucker, S.Y. (2014). Transforming pedagogies: Integrating 21st century skills and web 2.0 technology. Turkish Online Journal of Distance Education-TOJDE, 15(1), 166-173.

U.S. Department of Education. (2013). What works Clearinghouse TM-Let's Begin with the Letter People®. Washington, DC. Retrieved from http://ies.ed.gov/ncee/wwc/interventionreport.aspx?sid=271

Vygotsky, L. S. (1986). Thought and language (Kozulin, A., Ed.). Revised edition. Cambridge: MIT Press

Yahya Othman. (2007). Mengajar membaca. Teori dan aplikasi. Kuala Lumpur: PTS Profesional.

Zurinah Ismail. (2010). Meningkatkan kemahiran murid mengenal bentuk huruf kecil dalam kalangan 5 orang murid 4B melalui kaedah nyanyi dan lukis. Jurnal Kajian Tindakan Sekolah Rendah Negeri Johor, 3. 1-7. 